\title{
O fator humano: aproximações a partir da obra de Georges Friedmann
}

\section{The human factor: approaches from the work of Georges Friedmann}

Oscar Gallo ${ }^{1}$

\begin{abstract}
Resumo
O objetivo deste artigo é examinar a forma como a fisiologia do trabalho e a psicotécnica colocaram o "fator humano" no âmago dos processos produtivos. Mediante esta análise é possível compreender porque, num contexto de industrialização e auge do taylorismo, se materializaram uma higiene industrial, uma medicina do trabalhado e uma psicologia industrial preocupadas com as condições de trabalho e saúde dos trabalhadores. Ainda, examinar esse processo histórico permite resgatar o humanismo de Georges Friedmann e compreender, como observou Georges Canguilhem acerca da obra daquele sociólogo, a insuficiência metódica e doutrinária da racionalização e o fim do absoluto técnico.
\end{abstract}

Palavras-chave: Fator humano. Taylorismo. Medicina do trabalho. Georges Friedmann.

\begin{abstract}
The purpose of this article is to assess how the labor physiology and psycho technique placed the "human factor" in the productive processes core. Through this analysis it is possible to understand why a context of industrialization and the rise of Taylorism materialized an industrial hygiene, an occupational medicine and an industrial psychology concerned with working conditions and workers' health. Still, by examining this historical process, it is possible to rescue the humanism of Georges Friedmann and understand as mentioned by Georges Canguilhem about the work of that sociologist, the doctrinal and methodical insufficiencies of rationalization, the end of the absolute technical.
\end{abstract}

Key words: Human fator. Taylorism. Occupational medicine. Georges Friedmann.

\footnotetext{
${ }^{1}$ Historiador e Mestre em História pela Universidade Nacional da Colômbia. Doutorando no programa de Pós-Graduação em Historia da Universidade Federal de Santa Catarina - UFSC. Bolsista da Coordenação de Aperfeiçoamento de Pessoal de Nível Superior - CAPES. E-mail: oscargallovelez@gmail.com.
}

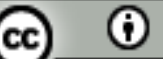

Esta obra foi licenciada com uma Licença Creative Commons - Atribuição 3.0 Não Adaptada 


\section{Introdução}

Em 1936, o sociólogo Georges Friedmann (1902-1977) publicou La crisis del progreso: esbozo de la historia de las ideas, 1895-1935 (1936/1977). Primeiro volume da série Maquinismo ${ }^{2}$ e Humanismo. Depois foram publicados Problemas humanos del maquinismo industrial (1947/1956) e A donde va el trabajo humano (1950/1961).

Quase dez anos, entre outubro de 1935 e junho de 1945, passaram-se entre o prefácio da crisis del progreso: esbozo de la historia de las ideas e o de Problemas humanos del maquinismo industrial. Sobre o contexto histórico da obra de Friedmann, são eloquentes as palavras de Freud (apud CANGUILHEM, 1999, p. 683), escritas entre 1937 e 1939: "Vivemos um momento particularmente curioso. Descobrimos com surpresa que o progresso firmou um pacto com a barbárie (tradução nossa)". ${ }^{3}$

A pesquisa de Friedmann se inscreve nesse contexto de ceticismo e reflexão sobre o progresso, o trabalho e a técnica. Mas ocorreu que, na mesma época em que se começava a vislumbrar a crise do progresso, materializou-se um método de organização ou racionalização industrial denominado taylorismo. Certamente, a mudança de paradigma produtivo e a introdução de formas de racionalização industrial haviam começado na virada do século XVIII, durante a denominada primeira Revolução Industrial ou período de introdução da energia a vapor, porém, foi somente no século XX, entre a Segunda e a Terceira Revolução Industrial, que se generalizou o trânsito do regime de acumulação extensivo ao regime de acumulação intensivo. Isto é, passou-se de um regime dependente do número de trabalhadores ou da superfície cultivada a outro, relacionado com a racionalização ou organização do trabalho em função do processo produtivo e do consumo dos indivíduos (MELLO E SILVA, 2010, p. 183).

\footnotetext{
${ }^{2}$ Para François Vatin essa expressão tem origem na primeira tradução do Capital ao francês, realizada no século XIX por Joseph Roy (VATIN, 2004a, p. 206). Roy, disse Vatin, traduziu maschinerie do alemão com machinisme. Maschinerie era a transposição da expressão machinery em inglês "complexo de máquinas". Dessa forma, Roy "involuntariamente sociologizou" a expressão.

${ }^{3}$ Exceto que se diga o contrário, todas as traduções do espanhol são nossas.
}

Cad. de Pesq. Interdisc. em Ci-s. Hum-s., Florianópolis, v.13, n.103, p.46-59, ago/dez 2012 
Contudo, quando se pensa em taylorismo, cometem-se vários erros de interpretação. Como sugere François Vatin, um deles consiste em desconsiderar as particularidades doutrinais do taylorismo, reagrupando os trabalhos de outros administradores, ergonomistas e especialistas do trabalho. Outro erro habitual consiste em assimilar o taylorismo como uma fase da história industrial do século $X X$, ou seja, "admitir [disse Vatin] que a organização industrial havia sido dominada, de começos do século $X X$ até nossos dias, por princípios de organização derivados explicita ou implicitamente do pensamento de Taylor (tradução nossa)" (VATIN, 2004b, p. 103). Enfim, deve-se superar a distorção produzida pelo taylorismo, que consiste em considerar esse ponto de origem das disciplinas relacionadas com a investigação do trabalho humano (VATIN, 2004b, p. 77).

Ideias desse tipo têm sido revistas por enfoques sociológicos e historicistas, demonstrando que a formação histórico-social e a correlação de forças de cada país fazem dos modelos produtivos cenários totalmente originais e híbridos (NEFFA, 1999). Já em 1947, Friedmann (p. 506) percebia que não existe uma racionalização e sim múltiplas racionalizações, pontos de vistas e condições concretas, ou como afirma Alain Lipietz, nas palavras de Mello e Silva:

\footnotetext{
...são as relações de classe em cada situação nacional particular que explicam a estabilização de determinada configuração, e não ao contrário, a maneira funcionalista, isto é, da arquitetura do sistema-mundo, ou da divisão internacional do trabalho, derivar-se-ia a "lógica" da periferia (MELLO E SILVA, 2010, p. 186).
}

Tudo isso para aclarar que o taylorismo ao qual se faz referência neste texto é aquele chamado de método Taylor, sistema Taylor, Scientific Magnagement, Administração Científica. Em outras palavras, equivale ao fenômeno histórico (ou doutrina técnica) vulgarizado nas três primeiras décadas do século $X X$ : o mítico taylorismo cujo êxito mediático se deve, em parte, à fascinação exercida pelos Estados Unidos sobre a Europa em torno dos anos 1920 do século passado. ${ }^{4}$

Todavia, acima de tudo, trata-se do taylorismo visto por uma geração de médicos, psicólogos e cientistas sociais, de intelectuais contemporâneos a Georges Friedmann, sociólogo que realizou uma etnografia ou etologia do homo faber nas

\footnotetext{
4 Sobre o fascínio produzido pelos Estados Unidos e o apogeu do taylorismo veja-se La crisis del progreso (FRIEDMANN, 1936/1977, pp. 160-176).

Cad. de Pesq. Interdisc. em Ci-s. Hum-s., Florianópolis, v.13, n.103, p.46-59, ago/dez 2012
} 
sociedades capitalistas e cuja conclusão, disse Canguilhem, foi a "dissipação de uma ilusão, a ilusão tecnicista, paralela à ilusão cientificista" (CANGUILHEM, 1947/2001, p. 111). Ele mostra, insiste Canguilhem (1947/2001, p. 118), as insuficiências metódicas e doutrinárias da racionalização, o fim do absoluto técnico.

Neste artigo, analisam-se as críticas dos psicotécnicos e fisiologistas do trabalho ao taylorismo. Examinar a forma como esses campos de saber colocaram o "fator humano" no âmago dos processos produtivos ajuda a compreender porque, num contexto de industrialização e auge do taylorismo, foi possível a configuração de diferentes campos de saber preocupados com a saúde e o corpo dos trabalhadores. Ainda, examinar esse processo histórico permite resgatar o humanismo de Georges Friedmann e compreender, como observou Georges Canguilhem acerca da obra daquele sociólogo, as insuficiências metódicas e doutrinárias da racionalização, como citado anteriormente.

\section{Taylorismo e psicofisiologia do trabalho}

Friedmann (1947/1956, p. 30) insinua que Frederick Winslow Taylor (18561915) e vários contemporâneos acreditavam sinceramente na possibilidade de impor uma ordem matemática ao caos do tempo e superar pela elevação incessante do rendimento os conflitos entre patrões e operários.

De fato, durante o século XIX pensava-se na possibilidade de resolver as diferenças entre capital e trabalho - a questão social ou questão operária mediante a compreensão do problema em termos macroscópicos; mas, na virada desse século o tecnicismo impôs a ideia de que as questões relacionadas ao trabalho podiam ser resolvidas no âmbito da empresa. A esse respeito, disse François Vatin:

\footnotetext{
A resolução da questão social já não corresponderia a uma ciência normativa (jurídica), que decretaria direitos e deveres sociais respectivos dos empregadores e os trabalhadores, mas sim a uma ciência positiva, que toma da mecânica, a fisiologia e a psicologia, e é capaz de fixar sobre a base de critérios objetivos, indiscutíveis, as normas e condições da produção (VATIN, 2004b, p. 81).
} 
Surpreendentemente, os efeitos do maquinismo industrial sobre a dignidade e o bem-estar do produtor escapavam às agudas observações da maioria dos pensadores do século XIX e seus herdeiros nas primeiras décadas do século XX (FRIEDMANN, 1947/1956, p. 22). ${ }^{5}$

Por contraste, o misticismo taylorista deparou-se com o apogeu de pesquisas realizadas por fisiologistas do trabalho e psicotécnicos. Tais pesquisas questionavam os princípios, leis e normas do Taylorismo, e constatavam os desacertos causados pela falta de rigor teórico, pelas insuficiências metodológicas, pelo empirismo vago e elementar. No entanto, apesar da simplicidade e por sua causa, deu-se a rápida difusão e hibridação do taylorismo no âmbito mundial. Era fácil, como insinua Jules Amar (apud VATIN, 2004b, p. 114) reduzir o problema da eficácia industrial à utilização ótima da "máquina humana".

Todavia, foi também a partir da raiz desse arcaísmo do pensamento de Taylor que se disseminou o estudo da atividade corporal e mental do homem na indústria, iniciado no século XIX por higienistas, médicos e psicólogos, porque, como disse Friedmann, "não era suficiente o exame abstrato e dogmático do método taylorista, era preciso diferenciar, com precisão matemática e por correlações verificadas, os graus de adaptação do indivíduo às condições de trabalho dadas" (FRIEDMANN, 1947/1956, p. 51).

Efetivamente, as pesquisas da psicologia experimental em torno dos caracteres particulares do indivíduo e seus métodos de testes foram decisivos para o exame científico do taylorismo. Assim, os aportes da psicologia experimental serviram de base para que no século $X X$ se desenvolvesse a psicofisiologia do trabalho. Friedmann destaca, nesse campo, Wilhelm Wundt (1832-1920), seus discípulos e os pesquisadores próximos de seu laboratório: Emil Kraepelin (18561926), Hugo Münsterberg (1863-1916), Édouard Toulouse (1865-1947), Victor Henri (1872-1940), Alfred Binet (1857-1911) e James McKeen Cattell (1860-1944). De

\footnotetext{
${ }^{5}$ Possivelmente escapou aos pensadores desse século, mas as práticas e oposição às formas de disciplinamento do tempo e a perda da autonomia no trabalho eram anteriores às imposições do sistema Taylor. Como lembra o historiador E.P. Thompson, os tecelões "mesmo antes do advento da energia de vapor [...] não gostavam das fábricas de teares manuais". A causa principal do descontentamento era a disciplina, a campainha, a sirene da fábrica, o controle do tempo que "esgotava os mais debilitados, prejudicava as atividades domésticas e impedia a ocupação a outras ocupações" (THOMPSON, 2002a, p. 166). E no caso dos artesãos o descontentamento era motivado pelo cotonifício, onde acima da exploração das crianças e a imoralidade, "reduzia-se o artesão industrioso a um estado de dependência" (THOMPSON, 2002b, p. 119).
}

Cad. de Pesq. Interdisc. em Ci-s. Hum-s., Florianópolis, v.13, n.103, p.46-59, ago/dez 2012 
Kraepelin, destaca-se o estímulo às monografias sobre ofícios e a seleção profissional mediante sua sistematização das curvas de trabalho e as pesquisas sobre as condições psicofisiológicas da atitude para o trabalho datilográfico. De Münsterberg, a insistência nas condições psicológicas do rendimento e, em outro nível, a ênfase no melhoramento das condições psicofisiológicas do trabalho em favor do beneficio cultural "que se irradia à vida econômica toda da nação" (FRIEDMANN, 1947/1956, p. 51-53).

Porém, não foram menos decisivos os estudos sobre a mecânica do corpo humano e a fisiologia dos séculos XVIII e XIX. Conforme Vatin, a origem epistemológica da psicopatologia do trabalho encontra-se na mecânica industrial do século XIX, cuja matriz teórica está vinculada à mecânica de Charles Augustin Coulomb (1736-1806) e aos estudos da respiração animal de Antoine Lavoisier (1743-1794) (VATIN, 2004b, p. 58-64). Dessa forma, na base da psicofisiologia do trabalho estão tanto os estudos de cinemática animal de Etiennes-Jules Marey (1830-1904) como o "trabalho fisiológico" - energia gasta por um músculo em contração - de Auguste Chauveau (1827-1917). Na perspectiva aberta por esses dois autores, disse Vatin, a fisiologia do trabalho se desenvolveu na virada do século XIX na França, Alemanha, Itália e Estados Unidos. A nova perspectiva

\footnotetext{
intentava compreender a natureza intima do 'motor animal': suas engrenagens (os órgãos), seus combustíveis (os alimentos), seu processo complexo de combustão. Assim, a termodinâmica, ao integrar o conceito de trabalho no mais geral de energia, longe de romper com suas raízes antropomórficas, abriu o caminho para a fisiologia e, portanto, ao estudo "científico" da atividade humana (VATIN, 2004b, p. 62).
}

Ainda, acrescenta Vatin, nos anos seguintes deu-se o trânsito do trabalho fisiológico ao trabalho psíquico. Esse deslocamento epistemológico está no cerne das pesquisas da psicofisiologia do trabalho da primeira metade do século XX. De fato, a psicofisiologia do trabalho é uma prolongação da fisiologia do trabalho e a noção de fator humano nasce da prolongação da ideia de motor humano, ou seja, do trânsito da ideia de trabalho fisiológico à ideia de trabalho psicofisiológico.

Bebendo, então, dessas duas correntes, a psicofisiologia do trabalho propõe um projeto científico, que se pode resumir em três teses: primeiro, para resolver a questão social é preciso elaborar uma ciência positiva do trabalho baseada na física, na fisiologia e na psicologia; segundo, tal ciência deverá abordar ao mesmo tempo 
trabalho manual e trabalho intelectual, "num contexto em que o segundo tende a suplantar o primeiro"; finalmente, o conceito de fadiga por questões sociais e científicas é a ferramenta teórica em torno da qual se constrói essa nova disciplina. A fadiga surge como ponte entre a fisiologia e a psicologia, e forma de compreender o ponto de vista do trabalhador (VATIN, 2004b, p. 82).

Com efeito, preocupados com o estudo da fadiga, isto é, do organismo que trabalha e as condições e limites de seu funcionamento, os primeiros fisiologistas do trabalho demonstraram que as observações de Taylor eram muito rudimentares. A esse respeito, o psicofisiologista Jean-Maurice Lahy ${ }^{6}$ afirma que a lei da fadiga de Taylor era de uma simplicidade que raiava a indigência (FRIEDMANN, 1947/1956, p. 68). ${ }^{7}$ Jules Amar (apud VATIN, 2004b, p. 111) estava visivelmente convencido deste aspecto, quando constatava que nos trabalhos de "Taylor não há estudo fisiológico rigoroso do trabalho e as normas taylorianas de rendimento, definidas de maneira voluntarista, podem resultar perigosas para o organismo humano." 8

Igualmente, pesquisadores da época, como Josepha Joteyko, Edgar Atzler e Armand Imbert (1850-1922), foram muito críticos do sistema Taylor porque este desconsiderava o que havia de vital e humano no trabalho. ${ }^{9}$ Em contraste com o mecanicismo taylorista, as reflexões dos psicofisiologistas correspondiam a um

${ }^{6}$ Cabe mencionar alguns dos psicólogos e fisiologistas destacados por Friedmann: Jean-Maurice Lahy (1872-1943), Jules Amar (1879-1935), Edgar Atzler (1887-1938), Arnold Durig (1872-1961), Edgar Atzler (1887-1938), Armand Imbert (1850-1922), Otto Lipmann (1880-1933), Friedrich Sander (1885-1938), Charles Samuel Myers (1873-1946), Armand Imbert (1850-1922), Etiene-Jules Marey (1830-1904), Auguste Chauveau (1827-1927), Henri Laugier (1888-1973), Archibald Hill (1886-1977), Lawrence Henderson (1878-1942), entre outros.

${ }_{7}$ Disse Taylor em The principles of Scientific Management "A lei mostra que, para cada um dos movimentos, o trabalhador só pode ficar sob o peso durante certa parte do dia [...] À medida que a carga se torna mais leve, aumenta a proporção de tempo que o carregador pode conduzi-la [...]. Diminuindo-se o peso, maior é o tempo que pode o homem conduzi-lo, até que, finalmente, reduz-se tanto que é carregado durante todo o dia sem fadiga [citado do original de 1919, porém para a tradução nos baseamos na versão brasileira (TAYLOR, 1966)]" (TAYLOR, 1911/1919, p. 53). Ou seja, uma relação inversa entre carga e tempo de carga. Em termos fisiológicos acrescenta: "Por todo o tempo em que o homem está sob esforço de sustentar peso, os tecidos dos seus músculos experimentam alterações e há necessidade de repetidos períodos de descanso para que o sangue possa fazer voltar esses tecidos à sua situação normal" (TAYLOR, 1911/1919, p. 53). Ante essas palavras afirma Friedmann "Nada mais!" (FRIEDMANN, 1947/1956).

${ }^{8}$ Porém, Jules Amar, quando sugere o rendimento da máquina humana, está mais próximo do mecanicismo questionado por outros psicofisiologistas como Armand Imbert. Sobre este tema, ver Armand Imbert (1850-1922), la science du travail et le paix sociale (LE BIANIC e VATIN, 2007, p. 11).

${ }^{9}$ Essa inclinação em direção à psicologia levou ao fracasso da psicofisiologia em seu projeto de compreender a fadiga. A fadiga era uma noção prática cuja compreensão não era possível nem por métodos fisiológicos ou psicológicos (VATIN, 2004b, p. 71-74). Porém, esse impasse não era exclusivo da psicofisiologia, ele abarca todas as ciências industriais do momento. A solução esteve na sociologização da noção da fadiga. Esse foi o enfoque de Friedmann.

Cad. de Pesq. Interdisc. em Ci-s. Hum-s., Florianópolis, v.13, n.103, p.46-59, ago/dez 2012 
deslocamento epistemológico do conceito de "trabalho" ao de "fadiga", ou seja, encontra-se uma mudança no objeto de reflexão: agora importava a dimensão nervosa da atividade muscular (VATIN, 2004b, p. 64).

$\mathrm{Na}$ senda dessa tradição, que superava o frágil empirismo do taylorismo, as pesquisas realizadas pelos psicofisiologistas do trabalho controvertem ou acrescentam várias das linhas de pensamento de Taylor, entre as quais podemos mencionar:

- Os métodos padronizados combinados com estímulos financeiros impossibilitavam descobrir a diferença entre método e incentivo.

- Os movimentos padronizados para obter um melhor rendimento não eram aplicáveis a diferentes operários nem ao mesmo indivíduo em diferentes momentos.

- A supressão de alguns movimentos podia ser útil para economizar energia física, mais significava desgaste psíquico; era preferível a facilidade à velocidade.

- A procura exclusiva pelo rendimento degenerava a pesquisa, tornando-a "um vulgar procedimento de intensificação".

- O fetichismo de "os tempos mortos" esquecia que os "instantes de atividade psicológica" podiam ser "tempos vivos" se confrontados pelas exigências do organismo e da produção. ${ }^{10}$

- O desconhecimento dos problemas psicológicos da mão de obra fez pensar que o mérito da direção científica estava em regular a coerção e o estímulo, o chicote e as guloseimas (FRIEDMANN, 1947/1956, pp. 59-71).

- A relação de força espontânea era favorável ao empregador e não ao trabalhadador, como acreditava Taylor.

- Para humanizar a tarefa era necessário intervir no meio ambiente de trabalho. "Decompô-lo em seus elementos principais: ventilação, temperatura, umidade, iluminação, ruído" (FRIEDMANN, 1947/1956, p. 113).

\footnotetext{
${ }^{10}$ Para Imbert, por exemplo, o trabalhador tinha consciência intuitiva de sua economia corporal, o bom operário era aquele que produzia mais e cansava-se menos (VATIN, 2004b, p. 87; LE BIANIC e VATIN, 2007, p. 12).

Cad. de Pesq. Interdisc. em Ci-s. Hum-s., Florianópolis, v.13, n.103, p.46-59, ago/dez 2012
} 
- O rendimento dependia da comodidade do trabalhador, isto é, a máquina precisava ser adaptada a ele (FRIEDMANN, 1947/1956, p. 127).

- Existem ritmos naturais e variáveis individuais que se opõem ao ritmo dogmático da estandardização. Pretender o one best way é "contrário a todas as considerações humanas" (FRIEDMANN, 1947/1956, p. 207).

Em síntese, o "exame científico" realizado por esses psicofisiologistas confirmava a falta ou ausência total de rigor teórico; as insuficiências metodológicas; o empirismo vago e elementar dessa pseudociência símbolo da modernidade industrial. Todavia, à notável indigência e risco do sistema Taylor, os psicofisiologistas do trabalho opuseram o "racionalismo biológico". ${ }^{11}$

O racionalismo biológico procurava, de um lado, definir as condições ótimas de trabalho para um mínimo de desgaste e fadiga e, por outro, adaptar as necessidades do organismo ao meio ambiente de trabalho (FRIEDMANN, 1947/1956, p. 78). Friedmann situa esses estudos num horizonte mais amplo de emergência do "movimento científico do fator humano". Assim, disse ele, com o fator humano reaparece a unidade do homem, que o mecanicismo de Taylor havia querido ignorar (FRIEDMANN, 1947/1956, p. 75).

Mesmo sendo positiva, a visão desse movimento do fator humano, mediante a inserção dos fatores biológicos e psíquicos no cerne dos processos produtivos, não é suficiente para Friedmann, porque atrelados à linha de montagem estão um fato técnico e um fato psicológico, somados a um fato social. $\mathrm{O}$ particularismo e desconhecimento da realidade social, precisamente, explicam o fracasso da psicofisiologia. As intenções desse campo de saber chocam a resistência dos fatos sociais e as estruturas econômicas e sociais em que se enquadram. Em função de um racionalismo biológico não é possível esquecer que o operário é atravessado por vínculos diversos: oficio ou profissão, família, sindicatos, classe social (FRIEDMANN, 1947/1956, p. 509-515).

Não existe a possibilidade de organizar metodicamente as operações industriais. A tarefa "normal" definida pelo operário submetido à cronometragem, na realidade pode estar muito longe do normal (FRIEDMANN, 1947/1956, p. 56). Já que o melhor movimento não é o melhor para todos, "há que admitir diferenças

\footnotetext{
${ }^{11}$ Tipos de racionalismo biológico podem ser identificados na história da medicina social na Inglaterra (PORTER, 1996).

Cad. de Pesq. Interdisc. em Ci-s. Hum-s., Florianópolis, v.13, n.103, p.46-59, ago/dez 2012
} 
pessoais". Aliás, o operário pode descobrir uma série de movimentos melhor adaptados a suas exigências físicas e mentais (ibidem, p. 59). Tudo isso se condensa num problema sociológico, em que têm papel determinante o sistema de valores e a consciência operária. No âmago do problema está "a resistência dos operários às medidas impostas do exterior" (CANGUILHEM, 2001, p. 114).

Isso conduz a uma invalidação tanto das normas de rendimento técnico, como das experiências artificiais em que estão sustentadas as pesquisas dos psicofisiologistas. Tornam-se igualmente obsoletas diversas facetas do taylorismo, tais como the one best way, a média em uma tarefa idêntica, a fadiga normal e a pausa. Em outros termos, no interior da fábrica se encontram três tipos de lógica, a do preço de custo, a do rendimento, a do sentimento:

\begin{abstract}
Esta última [disse Elton Mayo] que é a dos executantes, combina mal com as duas primeiras que os dirigentes conseguem bastante facilmente conciliar. O comportamento operário se revela como um dado rebelde à previsão e ao cálculo. A prática de restrição de rendimento é um sintoma da não integração do operário à empresa. Acredita-se poder remediar isso pelo desenvolvimento dos serviços sociais, clubes, sociedades esportivas. Mas é claro que a insuficiência dessas práticas revela a incapacidade em que se encontram os investigadores ('enquêteurs'), agentes a serviço da empresa, de ver a empresa com olhos de operários, de ver a empresa na sociedade, no lugar de fazer coincidir a sociedade e a empresa (MAYO apud CANGUILHEM, 1947/2001, p. 120).
\end{abstract}

$\mathrm{Na}$ atualidade, uma questão central das ciências sociais e administrativas é que contornos dar a uma ciência prática da organização industrial (VATIN, 2004b). De fato, essa dificuldade em contornar seu objeto procede, em parte, como destaca Canguilhem na citação anterior, da incapacidade de incorporar o "fator humano" ou "recurso humano" às lógicas da "ciência administrava". Este aspecto, que já era parcialmente colocado pelos psicotécnicos e fisiologistas do trabalho, foi retomado na sociologia do trabalho por Friedmann como eixo de seu projeto intelectual, nos anos 1930 e 1940.

Resta dizer que no mesmo horizonte dessa posição crítica da psicofisiologia do trabalho desenvolveram-se ideias eugênicas. Assim, as histórias do movimento do fator humano e da medicina do trabalho na França estão unidas à luta pela natalidade e à defesa da raça num contexto de entreguerras, em outras palavras, à incorporação de um tipo de eugenismo no marco da organização científica do trabalho (BUZZI, DEVINCK e ROSENTAL, 2006, p. 18-29). Porém, neste texto, 
recupera-se na obra de Georges Friedmann, principalmente, a crítica ao taylorismo desses primeiros psicofisiologistas, porque nesse contexto intelectual se situam tanto o surgimento do conceito de fator humano como as significativas mudanças na forma de compreender a fadiga dos trabalhadores, pilares da medicina do trabalho.

\section{Considerações finais}

No prefácio do livro La crisis del progreso: esbozo de la historia de las ideas, 1895-1935, Friedmann descreve a crise das ideologias do progresso, o paroxismo do período entreguerras, a esperança provocada pela experiência soviética e o possível relevo do capitalismo (FRIEDMANN, 1936/1977). Assim como para outros da geração, a tragédia da Grande Guerra e a posterior Revolução conduziu a uma exaltada mobilização das ideias marxistas e dos valores socialistas no contexto soviético ${ }^{12}$. No entanto, o avanço do século, a Segunda Guerra e o "socialismo real" desiludem a Friedmann que, como observa François Vatin, encontra nas ciências biológicas, na psicologia e nas ciências sociais o potencial para re-humanizar o trabalho (VATIN, 2004a, p. 220). É uma trajetória intelectual que, em palavras de Vatin, atravessa três etapas: um marxismo positivista, um humanismo romântico e um espiritualismo (VATIN, 2004a). O texto La crisis del progreso corresponde à fase intelectual de marxismo positivista e o texto Problemas humanos del maquinismo industrial à fase do humanismo romântico. Daí, em parte, seu otimismo e, em alguns casos, benevolência frente às ideias desses médicos e psicólogos do trabalho.

Sob essa perspectiva humanista, Friedmann sugere a liberação do potencial do indivíduo, uma normatividade em harmonia com o sentido que o homem dá a sua vida, ou seja, o primado do humano sobre o mecânico; do social sobre o humano; do vital sobre o mecânico; dos valores sobre a vida (CANGUILHEM, 1947/2001, p. 120).

\footnotetext{
${ }^{12}$ Marx e Engels, durante o período entreguerras, converteram-se em referências legitimas dentro da universidade francesa. No campo da sociologia houve um distanciamento com respeito às críticas ao marxismo de Emile Durkheim, Célestin Bouglé ou Maurice Halbwachs, surgindo assim uma produção sociológica engajada com a filosofia soviética. Friedmann corresponde a esse novo horizonte em que se vinculam a carreira de militante ou simpatizante com o Partido Comunista Francês e a carreira universitária. Entretanto, a estalinização e as fortes críticas a seu livro De la Sainte Russie à l'U.R.S.S (1938), levam-no a repensar sua simpatia, papel e autonomia do intelectual no regime soviético (GOUARNÉ, 2012, p. 2-8).

Cad. de Pesq. Interdisc. em Ci-s. Hum-s., Florianópolis, v.13, n.103, p.46-59, ago/dez 2012
} 
À sombra do humanismo que arvora Friedmann, é legitimo repensar em termos etnográficos o desenvolvimento industrial do Ocidente, porque em sua lógica existe uma defesa espontânea e primitiva frente à subordinação exclusiva do biológico ao mecânico, uma valorização positiva da adaptação das normas técnicas ao corpo do trabalhador (CANGUILHEM, 1952, p. 158).

A obra de Friedmann, através de seus trabalhos dos anos 1930 e 1940 acerca do taylorismo, foi inspiradora para as pesquisas contemporâneas sobre a temática. De fato, seus descobrimentos e críticas ao taylorismo marcaram profundamente, de acordo com Vatin, o debate francês sobre o taylorismo nos anos 1970. Entretanto, as facetas do itinerário intelectual de Friedmann correspondem a um horizonte muito mais vasto, que não é exclusivamente a sociologia do trabalho. Com efeito, as análises sobre a crise do progresso, a racionalidade industrial e as limitantes do movimento do fator humano, remetem ao debate sobre o lluminismo, a racionalidade científica e técnica, com seus efeitos despóticos e com suas pretensões de universalidade, aspectos centrais, segundo Foucault, em toda a filosofia contemporânea e origem da história da ciência (FOUCAULT, 2007). 


\section{REFERÊNCIAS}

BUZZI, S.; DEVINCK, J.-C.; ROSENTAL, P.-A. La santé au travail, 1880-2006. Paris: La Découverte, 2006.

CANGUILHEM, G. Meio e normas do homen no trabalho. Pro-posições, v. 12, n.2-3 (35-36), p. 109-121, jul.-nov. 1947/2001. Milieu e normes d'homme du travail. Cahiers internatinaux de sociologia. Aux. Ed. Du Seuil. Deuxième Annèe, 1947, p. 120-136.

CANGUILHEM, G. La connaissance de la vie. París: Hachette, 1952.

CANGUILHEM, G. La decadencia de la idea de progreso. Revista de la Asociación Española de Nueropsiquitría, v. XIX, n. 72, p. 669-683, 1999.

FOUCAULT, M. La vida: la experiencia y la ciencia. In: GORGI, G.; RODRÍGUEZ, F. Ensayos sobre biopolítica. Excesos de vida. Buenos Aires: Paidós, 2007. p. 4157.

FRIEDMANN, G. La crisis del progreso: Esbozo de la historia de las ideas (18951935). Barcelina: Laia, 1936/1977.

FRIEDMANN, G. Problemas humanos del maquinismo industrial. Buenos Aires: Suramericana, 1947/1956.

GOUARNÉ, I. Engagement philosoviétique et posture sociologique dans l'entredeux-guerres: le rôle politico-intellectuel de George Friedmann. Sociologie du travail, Paris, 2012. ISSN Doi: 10.1016/j.soctra.2012.06.002.

LE BIANIC, T.; VATIN, F. Armand Imbert (1850-1922), la science du travail et le paix sociale. Travail et Emploi, Paris, p. 7-19, jul.-set. 2007. 
MELLO E SILVA, L. Sobre algunas influências teóricas na construção de um tema: trabalho e classe trabalhadora na literatura recente. Revista Mundos do Trabalho, v. 2, n. 3, p. 181-205, jan.-jul. 2010.

NEFFA, J. C. Crisis e emergencia de nuevos modelos productivos. In: GARZA, E. D. L. Los retos teóricos de los estudios del trabajo hacia el siglo XXI.

México/Buenos Aires: CLACSO, ASDI y Universidad Autónoma de Aguas Calientes, 1999. p. Disponível em:

<http://bibliotecavirtual.clacso.org.ar/ar/libros/cyg/trabajo/neffa.rtf>. Acesso em: 22 jul. 2010.

PORTER, D. Social medicine and the new society: Medicine and Scientific Humanism in mid-Twentieth Century Britain. Journal of Historical Sociology , v. 9, n.2, p. 168-187, jun. 1996.

TAYLOR, F. W. The principles of Scientific Management. New York: Harper \& Brothers, 1911/1919.

TAYLOR, F. W. Principios de administracao cientifica. São Paulo: Atlas, 1966.

THOMPSON, E. P. A formação da classe operária inglesa: A maldição de Adão. $4^{\mathrm{a}}$ ed. Rio de Janeiro: Paz e Terra, 2002a.

THOMPSON, E. P. A formação da classe operária inglesa: a força dos trabalhadores. $4^{\mathrm{a}}$ ed. Rio de Janeiro: Paz e Terra, 2002b.

VATIN, F. Machinisme, marxisme, humanisme: Georges Friedmann avant et aprèsguerre. Sociologie du travail, Paris, v. 46, n. 2, p. 205-223, 2004a.

VATIN, F. Trabajo, ciencias y sociedad: ensayos de sociologia y epistemología del trabajo. Buenos Aires: Lumen, 2004b.

Artigo:

Recebido em: 19/11/2012

Aceito em: 20/12/2012 